\title{
Trends in species causing fungaemia in a tertiary care medical centre over 12 years
}

\author{
Trends im Erregerspektrum bei Fungämien in einer Großklinik \\ über eine 12-Jahresperiode
}

Preeti N. Malani, Suzanne F. Bradley, Rhonda S. Little and Carol A. Kauffman

Key words. Candida albicans, Candida glabrata, fungaemia, candidaemia, fluconazole.

Schlüsselwörter. Candida albicans, Candida glabrata, Fungämie, Candidämie, Fluconazol.

Summary. Trends in the species of yeast causing fungaemia over a 12-year period at a large tertiary care medical centre were reviewed. A total of 966 unique episodes of fungaemia occurred in 898 patients. There was an overall trend toward fewer fungaemic episodes due to Candida albicans and more due to Candida glabrata and Candida parapsilosis. However, C. albicans remained the predominant species causing fungaemia, and the proportion due to other species varied from year to year. Candida glabrata was disproportionately isolated from older adults, whereas C. parapsilosis was common among neonates and infants. The trends of increasing isolation of C. glabrata and decreasing isolation of C. albicans were associated with increasing usage of fluconazole, but changes in the proportion of fungaemias due to other species appeared to have no association with fluconazole usage.

Zusammenfassung. Über eine 12-Jahresperiode hin wurden in einer Großklinik die Hefeisolate von Fungämie-Patienten statistisch erfasst. Bei 898 Patienten wurden 966 FungämieEpisoden beobachtet. Insgesamt zeigte sich ein Trend zu weniger Fungämie-Episoden durch Candida albicans und zu mehr durch Candida

Divisions of Infectious Diseases and Geriatric Medicine, Department of Internal Medicine, Veterans Affairs Healthcare System, University of Michigan Medical School, Ann Arbor, Michigan, USA.

Correspondence: Professor Dr Carol A. Kauffman, VA Healthcare System, 2115 Fuller Road, Ann Arbor, MI 48105, USA. Tel: + 1-734-761-7984 Fax: + 1-734-769-7039 E-mail: ckauff@umich.edu glabrata und Candida parapsilosis. Trotzdem blieb C. albicans die dominante Art als FungämieErreger; der Anteil anderer Hefearten variierte von Jahr zu Jahr. Candida glabrata wurde relativ häufiger von älteren Patienten isoliert, C. parapsilosis häufiger von Neugeborenen und Kindern. Die Trends zunehmender Isolierung von C. glabrata und sinkender Isolierungshäufigkeit von C. albicans waren mit dem steigenden Einsatz von Fluconazol assoziiert. Änderungen in den Anteilen der Fungämie-Fälle durch andere Arten zeigten jedoch keine Beziehung zum Fluonazol-Einsatz.

\section{Introduction}

During the past 20 years nosocomial fungaemias have increased dramatically; Candida species are now the fourth most common cause of nosocomial blood stream infections in the United States [1]. Recently, the proportion of candidaemias due to non-albicans species has been noted to be increasing at some medical centres $[2,3]$. Especially notable is an increase in Candida glabrata and Candida krusei [2-6]. In a few centres, the use of fluconazole has been associated with the increase in fungaemias due to C. glabrata and C. krusei [3, 4, 6]. However, these centres primarily care for oncology and bone marrow transplant patients and so it may not be valid to generalize these findings to a general hospital population. To establish whether similar trends have occurred in a general hospital setting, we reviewed trends over 12 years in the species of yeast causing fungaemia at a large tertiary care 
adult and paediatric medical centre, and we evaluated the association of fluconazole use with these trends.

\section{Methods}

A retrospective review of microbiology laboratory records identified all fungaemias among patients hospitalized at the University of Michigan Medical Center between January 1988 and December 1999. An episode of fungaemia was defined as at least one blood culture that was positive for yeast; repeated isolation of the same yeast species from the same patient within 4 weeks was considered to be the same episode. Blood cultures were performed using the DuPont Isolator System (E.I. DuPont, Wilmington, DE, USA) from 1988 to mid-1992, and the BacT/ Alert System (Organon Teknika Corporation, Durham, NG, USA) from mid-1992 to 1999. Isolates that formed germ tubes were identified as Candida. albicans; further identification was performed using the API 20C System (bioMérieux Vitek, Hazelwood, MO, USA). Grams of fluconazole, both intravenous and oral formulations, dispensed to inpatients was determined from records of fluconazole purchases by the pharmacy.

Data were expressed as median or mean $\pm \mathrm{SD}$ The chi-square test was used to test for differences among dichotomous values. Analysis of variance was used to test for the association between fluconazole use and species isolated.

\section{Results}

During the 12-year period, a total of 2557 yeasts were isolated from blood cultures; there were 966 unique episodes of fungaemia that occurred in 898 patients. The median age of patients with fungaemia was 42 years (range, 1 day -100 years). Fifty-four per cent of patients were male. One hundred and 39 patients $(15 \%)$ were $\leq 1$ year old, including $44(5 \%)$ who were neonates, and 244 patients $(27 \%)$ were $\geq 60$ years old. Twenty-two episodes of polymicrobial fungaemia were identified; in 20 episodes, two species of yeast were isolated, and in two episodes, three species of yeast were found. Multiple separate episodes of fungaemia were documented for 27 patients; 21 had two distinct episodes and six had three or more episodes. One of these patients had 10 unique episodes during the 12-year period.

The mean number of fungaemias per year $(80 \pm 10)$ was consistent throughout the 12-year period. The change from the lysis centrifugation system to the automated BacT/Alert system did not result in differences in the total number of fungaemias each year. However, there were variations noted in the percentages of different species that were isolated each year. Overall, C. albicans remained the predominant species causing fungaemia throughout the study period, but the proportion decreased from $63 \%$ of fungaemias in 1988 to $43 \pm 7 \%$ over the last 4 years of the study (Fig. 1). This was accompanied by a corresponding increase in non-albicans species in these same periods $(P=0.0001)$. The greatest increases were seen for $C$. glabrata, which increased from 10\% of fungaemias in 1988 to $20 \pm 7 \%$ in 1996-99, and C. parapsilosis, which increased from $5 \%$ in 1988 to $18 \pm 3 \%$ in 1996-99. No episodes of C. krusei fungaemia were identified prior to 1992, but after that year, C. krusei accounted for a mean of $3 \pm 2 \%$ of fungaemias each year.

Candida glabrata was disproportionately isolated from older adults (Fig. 2). Of the total of 134

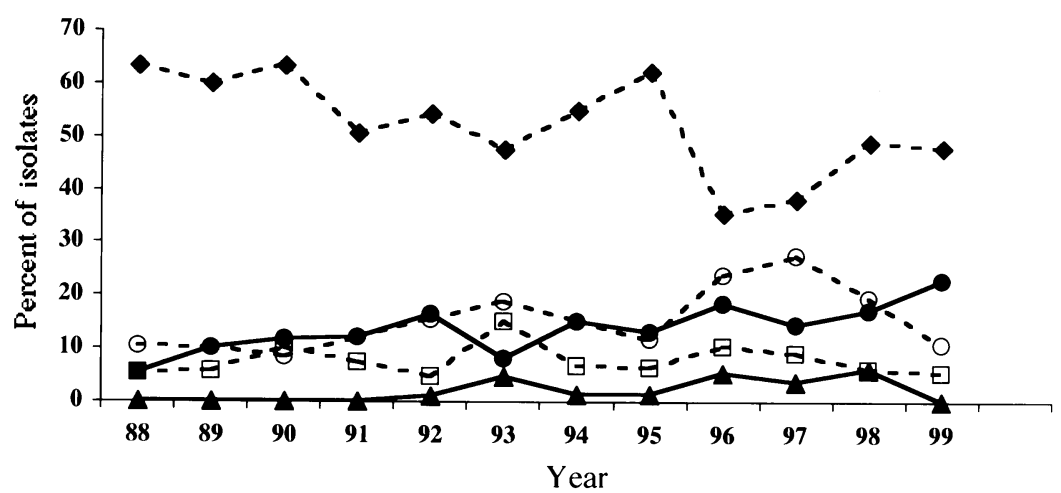

Figure 1. Percentage of different species causing candidaemia over a 12 -year period at a tertiary care medical centre. - - $\bullet-$, Candida albicans; - -О- -, C. glabrata; - - - C. parapsilosis; - - $\square-$-, C. tropicalis; - $\boldsymbol{\Delta - , ~ C . ~ k r u s k e i . ~}$ 
unique episodes of C. glabrata fungaemia, 71 (53\%) were in those $\geq 50$ years of age $(P=0.002)$, and $49(37 \%)$ were in those $\geq 60$ years of age $(P=0.01)$. Among neonates and infants, C. parapsilosis was a major pathogen. Of 121 unique episodes of $C$. parapsilosis fungaemia, 35 $(29 \%)$ were in the 139 patients who were $\leq 1$ year old $(P=0.0001)$. These age-related findings were consistently noted throughout the 12 years of the study.

Fluconazole, which was licenced in March 1990, was increasingly prescribed for inpatients at the University Hospital during the next 9 years (Fig. 3). An association was found between fluconazole usage and increased isolation of $C$. glabrata $(P=0.03)$, as well as decreased isolation of C. albicans $(P=0.04)$. Changes in other Candida species that caused fungaemia, including $C$. krusei, were not associated with fluconazole usage.

\section{Discussion}

Our data demonstrate a shift in the species of Candida causing fungaemia in a general hospital population during a 12-year period. The proportion due to $C$. albicans decreased whereas that due to other species, such as C. glabrata and C. parapsilosis, increased. These overall trends were superimposed on yearly variations in the proportions of fungaemias due to various species. In any given year, the percentage of fungaemias due to $C$. glabrata or $C$. parapsilosis varied; however, in every year, $C$. albicans remained the predominant species causing fungaemia.

Most recent surveys of candidaemia have focused on specific populations of high-risk, usually immunosuppressed patients [3, 4, 6-8], have assessed geographic differences [9], or have presented data accrued over only a few years from one or several institutions [2, 10-13]. There are only a few studies that have addressed long-term trends in species causing fungaemia in the general patient population cared for in a tertiary care centre [5]. In a study similar to ours that encompassed five university hospitals in the Netherlands over 9 years, Voss et al. noted an increase in isolation of $C$. glabrata, but not $C$. parapsilosis; $C$. albicans remained the most common species causing fungaemia [5].

The over-representation of infants less than 1 year of age among episodes of C. parapsilosis

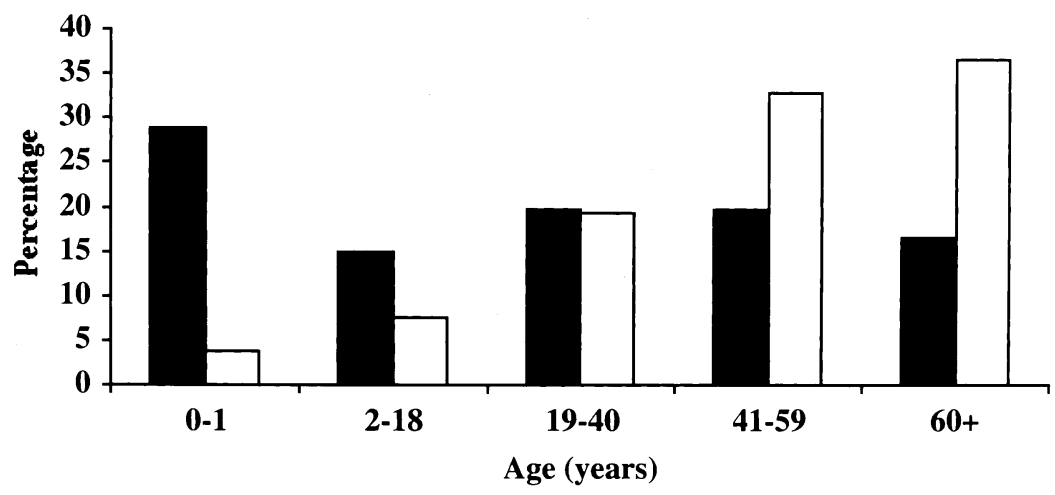

Figure 2. Effect of age on the distribution of episodes of fungaemia due to C. glabrata $(\square)$ and C. parapsilosis

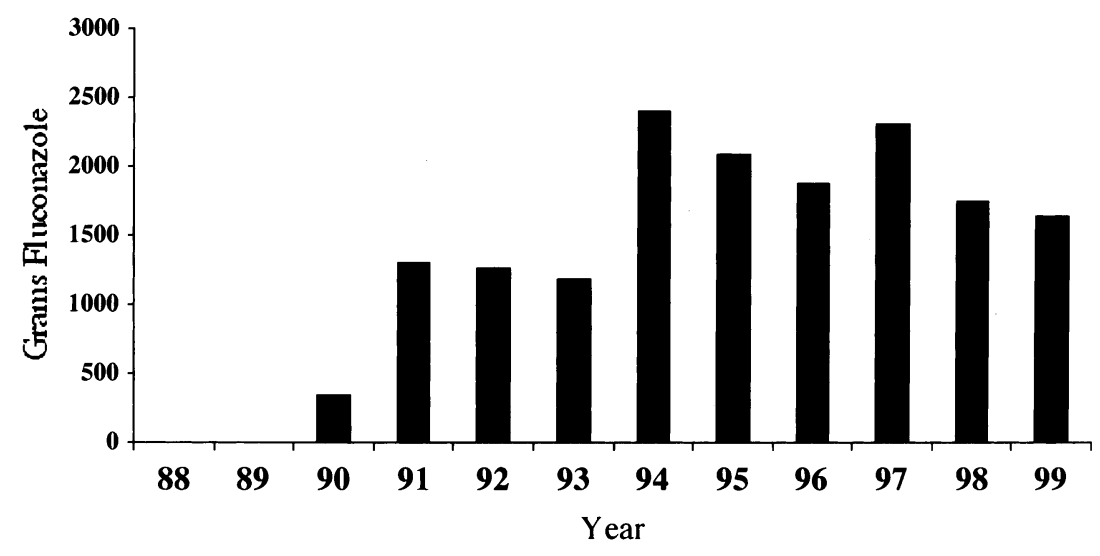

Figure 3. Grams of fluconazole used each year for inpatients at a tertiary care medical centre. 
fungaemia has been documented previously and is possibly a result of nosocomial transmission of this species in the intensive care unit setting $[11,13,14]$. The reason for the disproportionate number of $C$. glabrata fungaemias that occurred in older adults is not known, but has also been documented by others [15]. Although C. krusei was documented only after 1991, the number of episodes of fungaemia due to this species remained low throughout subsequent years, a finding similar to that reported by others [5]. In contrast, a few medical centres have found C. krusei to be an important cause of fungaemia in recent years [4].

The increased use of fluconazole in our medical centre was associated with changes in the species of Candida isolated from blood. However, it is likely that other events also played a role in the selection of different species. For example, in the last 2 years of the study, the increased proportion of candidaemias due to C. parapsilosis, a yeast species almost always susceptible to fluconazole, is not readily explained by increased fluconazole use. It is likely that changes in the proportion of fungaemias due C. parapsilosis also reflect nosocomial acquisition of this species, as has been noted by others [6].

The data we have reported are based on records from the microbiology laboratory, and thus, have certain inherent limitations. This study did not assess fluconazole use by individual patients or by specific high-risk groups, especially those likely to be on fluconazole prophylaxis. Prior studies of neutropenic and bone marrow transplant populations have documented the association of increased C. krusei and C. glabrata infections and decreased $C$. albicans infections with fluconazole prophylaxis $[3,4,6]$. Our study also did not address specific patient risk factors, which undoubtedly play a role in the selection of species causing fungaemia. However, this type of study does reveal overall long-term trends that should be helpful to physicians and antibiotic use committees in establishing guidelines for the appropriate use of antifungal agents.

\section{References}

1 Fridkin, S. K. \& Jarvis, W. R. (1996) Epidemiology of nosocomial fungal infections. Clin. Microbiol. Rev. 9, 499-511.
2 Nguyen, M. H., Peacock, J. E., Morris, A. J., et al. (1996) Thechanging face of candidemia: emergence of nonCandida albicans species and antifungal resistance. Am. $\mathcal{F}$. Med. 100, 617-623.

3 Abi-Said, D., Anaissie, E., Uzun, O., Raad, I., Pinzcowski, H. \& Vartivarian, S. (1997) The epidemiology of hematogenouscandidiasis caused by different Candida species. Clin. Infect. Dis. 24, 1122-1128.

4 Wingard, J. R., Merz, W. G., Rinaldi, M.G., Johnson, T. R., Karp, J. E. \& Saral, R. (1991) Increase in Candida krusei infection among patients with bone marrow transplantation and neutropenia treated prophylactically with fluconazole. N. Engl. F. Med. 325, 1274-1277.

5 Voss, A., Kluytmans, J. A. J. W., Koeleman, J. G. M., et al. (1996) Occurrence of yeast bloodstream infections between 1987 and 1995 in five Dutch University hospitals. Eur. F. Microbiol. Infect. Dis. 15, 909-912.

6 Marr, K. A., Seidel, K., White, T. C. \& Bowden, R. A. (2000) Candidemia in allogeneic blood and marrow transplant recipients: evolution of risk factors after the adoption of prophylactic fluconazole. F. Infect. Dis. 181, 309-316.

7 Viscoli, C., Girmenia, C., Marinus, A., et al. (1999) Candidemia in cancer patients: a prospective, multicenter surveillance study by the Invasive Fungal Infection Group (IFIG) of the European Organization for Research and Treatment of Cancer (EORTC). Clin. Infect. Dis. 28, 1071-1079.

8 Kunova, A., Trupl, J., Spanik, S., et al. (1995) Candida glabrata, Candida krusei, non-albicans Candida spp. and other fungal organisms in a sixty-bed national cancer center in 1989-93: no association with the use of fluconazole. Chemotherapy 41, 39-44.

9 Pfaller, M. A., Jones, R. N., Doern, G. V., et al. (1998) International surveillance of bloodstream infections due to Candida species: frequency of occurrence and antifungal susceptibilities of isolates collected in 1997 in the United States, Canada, and South America for the SENTRY Program. f. Clin. Microbiol. 36, 1886-1889.

10 Pfaller, M. A., Jones, R. N., Messer, S. A., et al. (1998) National surveillance of nosocomial blood stream infection due to species of Candida other than Candida albicans: frequency of occurrence and antifungal susceptibility in the SCOPE Program. Diagn. Microbiol. Infect. Dis. 30, 121-129.

11 Rangel-Frausto, M. S., Wiblin, T., Blumberg, H. M., et al. (1999) National Epidemiology of Mycoses Survey (NEMIS): variations in rates of bloodstream infections due to Candida species in seven surgical intensive care units and six neonatal intensive care units. Clin. Infect. Dis. 29, 253-258.

12 Price, M. F., LaRocco, M. T. \& Gentry, L. O. (1994) Fluconazole susceptibilities of Candida species and distribution of species recovered from blood cultures over a 5-year period. Antimicrob. Agents Chemother. 38, 1422-1424.

13 Stamos, J. K. \& Rowley, A. H. (1995) Candidemia in a pediatric population. Clin. Infect. Dis. 20, 571-575.

14 Kao, A. S., Brandt, M. E., Pruitt, W. R., et al. (1999) The epidemiology of candidemia in two United States cities: results of a population-based active surveillance. Clin. Infect. Dis. 29, 1164-1170.

15 Gumbo, T., Isada, C. M., Hall, G., Karafa, M. T. \& Gordon, S. M. (1999) Candida glabrata fungemia. Clinical features of 139 patients. Medicine (Baltimore). 78, 220-227. 